that does nothing to register and protect her ancient monuments."

It may be urged that we have the Ancient Monuments Protection Act, which Sir John Lubbock, after great labour, succeeded in passing through Parliament. This Act is valuable so far as it groes, but only 69 monuments in the British Islands (29 in England, 21 in Scotland, and $\mathbf{I} 9$ in Ireland) were specified in the schedule. Under Section 10 of the Act of 1882 , Her Majesty may, by Order in Council, make additions to the list of monuments protected by the Act. This power has, however, been taken advantage of only to a very limited extent. It has been exercised on six occasions between I887 and I892, and 31 monuments ( 7 in England, 17 in Scotland, and 7 in Ireland) have been brought under the Act. Dr. Murray definitely states that "the Government have, in fact, rendered the Act inoperative, as regards the future, by steadily declining to accept further monuments even when offered to them." Ireland has been more fortunate there are thus between 170 and 180 monuments in Ireland under public protection, as against 38 in Scotland and 36 in England.

Dr. Murray is not alone in his desire to see all our archæological remains preserved and described; but he has stated the case with enthusiasm and full knowledge in this little brochure.

Specialisation in scientific studies is necessary, but there is a great danger of weakness through sub-division. For example, archaeological remains are relegated to archæologists and antiquarians, who are tacitly held responsible for them. Why should not professed historians and all who desire to intelligently understand the culture history of their native land, as well as of mankind in general, feel that they too are responsible for the record and preservation of these historical data? Few branches of unapplied science are of more national importance, and it would be well if the wave of patriotism that is now astir could be partially diverted towards this truly patriotic object.

\section{THE INTERNATIONAL PHOTOGRAPHIC CATALOGUE AND CHART.}

$\mathrm{N}$ the month of May last year the permanent Comite International, for the execution of the Photographic Chart of the heavens, met at Paris to discuss various questions which had been left undecided at previous Conferences, and to inquire into the state of progress of the work of the various observatories participating in this international scheme. At these meetings, in addition to the members of the Committee, several guests were invited to be present and take part in the discussions.

The report of the proceedings, which has just been published, commences with a brief reference to the work of each of the observatories that is partaking in this scheme, the President (the late M. Tisserand) stating that the undertaking, as a whole, was in a satisfactory state of advancement. The report then refers somewhat in detail to the numerous questions that had been prepared for discussion at these May Conferences, from which we make the following brief abstracts.

With regard to the catalogue, the first resolution adopted, as the result of a special Committee of inquiry, composed of MM. Donner, Dunér, Jacoby, Paul Henry and Scheiner, was that the probable error of the values of the rectilinear coordinates measured on the plates ought to be as small as possible, and that the measures should be made such that this error should not exceed $\mathrm{O}^{\prime \prime} \cdot 20$.

It was further resolved to publish, as soon as possible the rectilinear coordinates of the stars photographed, and that this publication should also contain the data necessary for converting these results into equatorial No. I 436 , voL. 56] coordinates. The Committee expressed the desire that a provisional catalogue of right ascensions and declinations might be published by those observatories whose resources were sufficiently large. Each observatory is allowed to choose the positions of those stars of reference in the catalogues which appear the most convenient to them. For the calculation of the constants of the clichi's, a minimum, if possible, of ten stars of reference must be allowed, and the adopted positions of these stars should be published. It was decided to postpone to a later date the discussion relative to the question of using a uniform system of constants for all the observatories for the reduction of the stars to the epoch Igoo. All agreed, however, that an identical form of publication for all the observatories should be adopted, that of the catalogue of the Paris Observatory serving as the type. Each observatory can determine the photographic magnitudes, either by means of measurement or by estimation. The only stipulation the Committee imposes is that the methods employed must be such that the magnitudes in different observatories can be reduced to a common system.

With reference to the so-called photographic chart, five resolutions were adopted, namely :-

(I) That each observatory will be provided with a scale (furnished by. Captain Abney) of densities, which will be impressed on the plates simultaneously with the réseau, by which the sensibility of each plate for the luminous objects of different intensities will be controlled.

(2) For the construction of the chart, the second series of clichés-that is, those whose centres are of unequal declination-will be exposed three times for a period of thirty minutes each. The time of exposure may be diminished if a decided increase in the sensibility of the photographed plate be noticed.

(3) The Committee selects, as the best method of reproducing the chart, the photogravure on copper from the clichés, with three exposures on them, the original scale being doubled.

(4) Each observatory will make two contact glass positives of each negative, one of which will be preserved in the building at Breteuil, part of the Bureau International des Poids et Mesures.

The next meeting of the Committee will probably occur on the occasion of the Universal Exhibition, in the year 1900.

\section{NOTES}

THE announcement of the resignation of M. J. de Morgan, Director General of the Administration of Antiquities of Egypt, recently made by a contemporary, will be received with regret by many. It will be remembered that the duties of this gentleman were two-fold; he was supposed to excavate sites which promised good antiquarian results throughout Upper and Lower Egypt, and also to direct and manage the Ghizeh Museum near Cairo. It is not clear whether M. de Morgan has resigned both duties, but a well-founded rumour asserts that he is going to leave Egypt and to excavate in Persia on behalf of the French Government, who are said to have obtained a concession to clig for antiquities throughout the country, and to have leave to carry away whatever they may find. Whether M. de Morgan has severed his connection with Egypt wholly or partially matters very little relatively, but his resignation brings to the front the important question of what is to be done in the future about the conservation of the monuments which remain in situ, and those which are preserved in the National Museum. No one can deny that M. de Morgan has worked well in Egypt, and although much fault has been found with his "Catalogue" by those who have carefully read the work, none can deny that his excavations have been both thorough and successful, and that he has 